\title{
VELHAS E NOVAS QUESTÕES DA TRADUÇÃO NO ENSINO DE LÍNGUAS UM OLHAR SOBRE SALAS DE AULA COM LÍNGUAS DISTANTES
}

Elisa Figueira de Souza Corrêa é doutoranda em Estudos da Linguagem na PUC-Rio e bolsista do CNPq. É também professora de japonês e de português para estrangeiros. Entre 2012 e 2013, lecionou português para professores, alunos da graduação e da pósgraduação da Universidade de Hebei, na China.

E-mail: pehdefigo@gmail.com

\section{Resumo}

Este artigo trata do uso da tradução no ensino de línguas, fazendo breve revisão desta tradição e, em seguida, focando em questões relacionadas a seu uso, como a "tradução explicativa" e a "tradução pedagógica", com especial atenção para os casos em que L1 e LE são línguas distantes. Levantam-se também indagações sobre a viabilidade da tradução pedagógica caso o professor não compartilhe da L1 de seus alunos.

\begin{abstract}
This article is about the use of translation in language teaching. It reviews briefly this tradition and, then, focuses in issues related to its use as "explanatory translation" and as "pedagogical translation". It takes a particular look in cases in which students' L1 and foreign language are non-related languages. It also raises questions on the viability of pedagogical translation when the teacher does not share his students' L1.
\end{abstract}

\section{1) Introdução}

Este artigo marca o começo de uma pesquisa sobre o uso da tradução interlingual $^{1}$ no ensino de línguas não-maternas. Nessa pesquisa pretendo observar questões que possam surgir pelo fato de a língua materna (LM ou L1) dos alunos ser uma língua distante da língua por eles estudada, ou ainda questões devidas ao fato de o professor não ser proficiente na L1 de seus alunos.

Para começar a pensar tais questões, contudo, é importante relembrar a diferença situacional em que ocorre o estudo de uma língua. Se o aprendiz está cercado por ambiente de sua LM, utiliza-se a denominação língua estrangeira - LE; se está envolto pela língua em aprendizado, trata-se de segunda língua - L2.

Além disso, primeiramente, tenta-se rever brevemente a história do uso da tradução no ensino de línguas, partindo da Roma Antiga até os dias de hoje, passando pelo controverso século XX, quando a maioria dos métodos de ensino pretendeu banir completamente a L1 das salas de aula e, com ela, a tradução.

Num segundo momento, seguindo o paradigma teórico atual que revê aquele banimento, faz-se uma reflexão sobre por que e como a tradução deve ser utilizada em sala e, a partir daí, sobre contextos mais específicos, a saber, o uso da tradução no ensino de línguas estrangeiras distantes da L1 dos alunos.

Outro caso de interesse consiste na viabilidade de exercícios de tradução quando o professor não compartilha da L1 de seus alunos. Note-se, todavia, que, como este artigo é parte de uma pesquisa em andamento, não se pretende responder a todas as perguntas aqui levantadas. 


\title{
2) Breve contextualização histórica do uso pedagógico da tradução
}

Um dos primeiros exemplos de uso pedagógico da tradução se encontra na Roma Antiga, onde os exercícios conhecidos como imitatio eram utilizados pelos estudantes de oratória e de retórica para aperfeiçoarem seu estilo. Nas palavras de Douglas Robinson (2001, p. 111), "pedagogicamente, ela [imitatio] era usada para exercícios de revisão, nos quais os estudantes eram ensinados a escrever ou a discursar pela reescrita ou recitação de textos clássicos - alterando-os de alguma forma significativa, escolhendo novas palavras para dizer o mesmo".2

Embora, a princípio, esses textos clássicos pudessem ser textos latinos (os quais seriam, portanto, apenas parafraseados), é explicando tais exercícios que Marco Túlio Cícero (106 a.C. - 43 a.C.) defende explicitamente que os textos escolhidos sejam preferencialmente gregos - ou seja, exercícios de tradução para fins de aprendizado estilístico e de enriquecimento linguístico. Contando de sua própria experiência no livro terceiro Do orador (\$154-155), Cícero escreve:

\begin{abstract}
Quando jovem, costumava [...] pronunciar exatamente o mesmo assunto que lera com as palavras mais diversas que podia daquelas que lera. No entanto, percebi, posteriormente, que havia um problema nesse exercício: as palavras mais apropriadas a cada tema, assim como as mais distintas e as melhores, já haviam sido empregadas por Ênio, se me exercitava em seus versos, ou por Graco, se acaso houvesse me proposto algum discurso seu. Dessa forma, se empregasse as mesmas palavras, de nada me valeria; se usasse outras, seria um empecilho, já que me acostumaria a usar as menos apropriadas. Posteriormente, decidi, e disso me servi quando jovem, parafrasear os discursos gregos dos maiores oradores. Depois de lê-los, conseguia, ao traduzir em latim o que lera em grego, não apenas empregar as melhores palavras, ainda que de uso comum, mas também, por imitação, forjar alguns termos que eram novos aos latinos, contanto que fossem apropriados. (tradução de Scatolin, 2009, p. 172)
\end{abstract}

Para ele, então, a "imitação" de textos (gregos, no caso) proporcionaria tanto aperfeiçoamento linguístico/oratório, quanto instrução cultural, na medida em que a cultura grega era para ele um modelo a ser seguido. "Por terem sido os áticos apresentados a nós como dignos de imitação, discursar bem significa discursar ao modo ático" - diz o orador romano em outro lugar (Cícero; Vieira; Zoppi, 2011, p. 10).

Mas não só os oradores se utilizavam da tradução em seus estudos. O estudo de línguas e, especialmente, o estudo de grego e de latim clássico através da tradução foi uma prática corrente desde a Roma Antiga. No entanto, apenas no fim do século XVIII surgiu um método bem definido de ensino de línguas modernas a partir da tradução. Esse método ficou mais conhecido entre nós como Método da Gramática e Tradução (MGT), e consistia no seguinte: 
O MGT requer que os aprendizes se foquem em pontos gramaticais individualmente, os quais são ensinados dedutivamente. Sentenças de exemplo são então traduzidas tanto da quanto para a L2 [...] O MGT, portanto, se foca mais na exatidão e na escrita do que na língua falada, de modo que a língua é destrinchada e analisada ao nível de palavras, frases e sentenças individuais num primeiro momento. (Hall, 2011, p. 81-2)

Esse método, difundido principalmente pelas escolas ginasiais alemãs, se difundiu rapidamente por toda a Europa e Ocidente com grande sucesso, sendo utilizado ainda hoje, segundo alguns autores, e.g. Guy Cook (2009) e Graham Hall (2011). Segundo Konrad Macht (1994), o desenvolvimento desse então novo método e seu sucesso deveu-se ao movimento neo-humanista de Wilhelm von Humboldt (1767-1835), cujo objetivo maior era o desenvolvimento da mente, da consciência estética e da ética todos de acordo com os antigos ideais greco-romanos - dos jovens alunos, pouco importando a habilidade comunicativa na língua estudada. De fato, as línguas modernas eram mesmo consideradas inferiores e de menor valor em comparação ao latim e ao grego antigo. "Qualquer pensamento de promover habilidades práticas que pudessem ser de uso imediato na vida cotidiana tinha de ser descartado. O único objetivo do ensino de línguas era o desenvolvimento da mente" (Macht, 1994, n.p.). ${ }^{4}$

O primeiro manual para ensino de francês seguindo as tendências neohumanistas foi publicado em 1783, por Johann Valentin Meidinger. Dez anos depois, um manual de inglês seguia os passos daquele:

[o manual apresentava,] em cada lição, primeiro um conjunto de regras detalhadas em um item gramatical particular (e.g. os pronomes), seguido por pedaços de sentenças a serem traduzidas para a língua-alvo e por uma lista de equações de palavras. Exceto por algumas anedotas curtas e poemas no apêndice do livro, os estudantes nunca liam uma única sentença na língua estrangeira; eles tinham que construir a língua-alvo sinteticamente a partir das regaras e listas de palavras do livro. Dessa forma, os pupilos exercitavam suas memórias, aprendiam a fazer distinções gramaticais de acordo com a gramática latina e a lidar com os vários elementos linguísticos nas tarefas de tradução. (Macht, 1994, grifos nossos) $)^{5}$

Como se percebe, era uma prática voltada para a memorização no que se esperava ser um "treinamento mental" das crianças. Em 1834, com sucesso editorial inédito, Franz Ahn modificou o método de Meidinger retirando as explicações gramaticais detalhadas e as substituindo por listas de "sentenças modelares" (seguidas de tradução na LM) que ilustravam os pontos gramaticais e deveriam ser decoradas. É interessante notar que tais sentenças passaram a ser criticadas com o argumento de serem completamente desconexas. Veja-se, por exemplo, o par "You always interrupt me when I am speaking. You were coming from the tailor's as I was going to the shoemaker's" (Ahn apud Macht, 1994).

O MGT veio ter sua forma mais bem acabada e conhecida através da publicação do manual de inglês de J. Fölsing, em 1840. Esse era um meio termo entre os dois 
manuais anteriores, trazendo tanto a parte de gramática dedutiva quanto as sentenças para memorização, antes de partir para os exercícios de tradução. Esse manual tornou-se o modelo mais popular de ensino-aprendizagem de LE na segunda metade do séc. XIX.

Observe-se que a tradição de estudos gramaticais já se utilizava pesadamente do estudo de sentenças artificiais e sem sentido para análise. Conforme analisei em outro lugar (cf. Souza Corrêa, 2010), as causas para tal utilização se encontram em dois fatos. Primeiro, um erro na tradução de uma expressão usada nas gramáticas gregas que serviram de modelo para a tradição de estudos gramaticais latinos (e, posteriormente, de outras línguas ocidentais), a saber, a expressão autotelōs lógos. Para os gregos, isso indicava uma expressão autossustentada, graças a seus elementos semânticos e à sua função, dentro da totalidade de um texto, porém ela foi erroneamente traduzida por "frase completa", na qual "completa" tinha o sentido de "acabada, perfeita" (WEEDWOOD, 2008, p. 34-35). Esta ideia de "frase completa", então, é a mesma presente ainda hoje nas gramáticas normativas do português e que já figurava na gramática de Prisciano (séc. V), a qual se tornou manual de gramática preferido dos bancos escolares europeus por oito séculos.

A segunda causa ocorreu quando os estudiosos da linguagem, para se distanciarem da análise dos textos clássicos greco-romanos (i.e. pagãos) que eram, originalmente, o objeto do estudo gramatical, fundaram um hábito muito comum: formulavam sentenças sem levar em conta a sua naturalidade ou contextualização, e.g. Socrates albus currit bene (i.e. "o pálido Sócrates corre bem").

Acredito, então, que possivelmente devido a essa tradição secular da "frase completa", solta e desconexa, estudada nas gramáticas de língua latina e, mais tarde, nas de LMs europeias, não se tenha visto qualquer problema em se transportar o mesmo hábito para o ensino-aprendizagem de línguas estrangeiras. Como apresentado por Macht (1994), os métodos de ideologia neo-humanista dominaram o cenário alemão e, em grande parte, o resto do mundo ocidental, especialmente no século XIX. Ainda assim, não demorou para que surgissem também críticos ao MGT - embora esse método tenha continuado governando o ensino de línguas modernas em escolas e universidades, e os estudos dos autodidatas. À medida que o objeto de estudo principal deixou de serem línguas mortas como o grego e o latim, viu-se que o MGT se distanciava por demais das necessidades práticas, por exemplo, de estudantes adultos e de migrantes.

O domínio quase absoluto e a difusão sem par do MGT no mundo ocidental fizeram com que a reação a ele fosse também sem igual. Cook (2009, p. 113) identificou as críticas principais ao MGT feitas durante essa época: (a) desconsideração da língua oral; (b) incentivo a uma falsa noção de equivalência; (c) uso de sentenças isoladas e descontextualizadas, altamente artificiais; (d) dificuldade de tradução da L1 para a L2; 
(e) reforço do processamento via L1, com consequente fortalecimento da interferência da L1 na L2 e retardo na aquisição do processamento da L2 como um nativo.

A virada paradigmática ocorrida nessa época foi radical. Eis que, de método preferido, o MGT passou a ser o mais abominado, a ponto de ser renegado tudo que a ele remetesse ou a ele se assemelhasse. Por quase todo o século XX, então, os novos métodos de ensino de LE e L2 pregaram o uso exclusivo da língua estudada durante a aula e a proibição da tradução em qualquer de suas formas. Gramática e tradução foram postas de lado como vilãs, sendo esta completamente banida e aquela substituída tanto quanto possível por métodos com foco na oralidade, fosse pela produção espontânea ou na automação de frases (através de drills).

Tal reação desproporcional contra a presença da tradução no ensino L2/LE claramente não poderia durar muito. Kelly (apud Cook, 2009, p. 115), por exemplo, observa que o séc. XX foi único ao vilipendiar o uso da tradução no ensino de línguas. E já nos anos 1980, teóricos e professores perceberam o descabimento de tal situação, pois, a rigor, pode-se falar de uma impossibilidade - pelo menos em alguns casos - de se ensinar uma língua estrangeira sem jamais recorrer à L1. Nesse sentido, María Calvo \& Mark Ridd (2009, p. 161) explanam o papel da L1 na aquisição de LE como filtro e modelo, e ainda o relacionam com a tradução:

\footnotetext{
A tradução mental é um processo ou estratégia cognitiva que ocorre de forma natural na mente e que, portanto, dificilmente poderá ser evitado. [...] Bachmann (1994, p. 14) ressalva que investigações psicolinguísticas recentes estabelecem uma relação natural entre aprender uma língua e traduzi-la.
}

Assim, conforme diversos autores fizeram notar, banir a L1 da sala de aula pode gerar desconforto e ansiedade desnecessários para os alunos e também para professores cuja L1 não seja a língua estudada. Além disso, esses autores também criticaram o velho pressuposto, já superado pela pedagogia moderna, de o aluno ser uma tabula rasa (neste caso, linguística), sem conhecimento prévio sobre uma língua ou sobre todo o lado sócio-pragmático e cultural que a envolve. É uma realidade necessária para as teorias de ensino-aprendizagem de língua aceitar o fato de que todo conhecimento novo, seja linguístico, cultural ou qualquer outro, irá passar pelo filtro da L1 do aluno - filtro o qual está intrinsecamente ligado a toda sua experiência de vida.

\section{3) O uso da tradução em sala de aula}

Há diversas maneiras de perceber e de permitir o uso da tradução em sala de aula. Diversos autores costumam enumerar situações em que a comunicação docentediscentes é feita em L1, como casos de tradução em sala de aula, por exemplo. Tal tipo de tradução seria, para eles, justificável especialmente nos níveis iniciais. 
Atkinson (apud Romanelli, 2009, p. 210) chega a sugerir vários usos de tradução que facilitariam o andamento da aula, em vez de longas tentativas de explicações na língua em estudo. $\mathrm{O}$ autor explicita então o que denomina "os bons usos da tradução em sala": (a) explicar o significado de uma palavra mediante a tradução; (b) controlar a compreensão de uma estrutura da LE na LM; (c) permitir ou estimular os estudantes a traduzirem de uma palavra como controle de sua compreensão; (e) elucidar o vocabulário dando o equivalente na LM; (e) dar instruções relativas a uma atividade, na LM, facilitando a comunicação com os estudantes.

Embora seja possível concordar com Atkinson sobre as vantagens das práticas supramencionadas, concordo com Herbert Welker (2003, p. 4) quando este sugere que seria melhor denominar de outra forma esses tipos de uso, a fim de esclarecer os diferentes usos linguísticos possíveis em sala. Assim, Welker, citando Lavault, afirma que, para além da distinção já normalmente aceita entre "tradução profisssional" e "tradução pedagógica", seria possível estabelecer uma nova distinção no âmbito desta última:

[a tradução pedagógica], que ocorre em situações de ensino, é dividida [por Lavault] em "tradução explicativa" (que abrange todos os casos em que o professor recorre à LM) e "exercícios de tradução". Embora o professor, de fato, traduza palavras ou enunciados (para efeitos de explicação), chamo isso não de tradução mas de uso da língua materna. Deste modo, a tradução pedagógica restringe-se aos exercícios feitos pelos alunos. (WELKER, 2009, p. 4, grifos do autor)

Ou seja, Lavault subdividiu a tradução pedagógica em dois tipos - a tradução explicativa e os exercícios de tradução. Todavia, o que Lavault chamou de tradução explicativa Welker desconsiderou como um tipo de tradução e o renomeou como uso da língua materna, reservando então o nome tradução pedagógica para os exercícios de tradução.

Tal proposta me parece tanto mais razoável se lembrarmos que, na maioria das aulas de LE em que professor e alunos compartilham a L1, por mais que o professor possa de fato preferir usar a LE em questão, soa estranho chamar de "tradução" um momento em que todos os envolvidos estão, de fato, tão somente usando sua LM.

Imagine-se, por outro lado, uma aula de L2, por exemplo, de alunos estrangeiros que vêm estudar português no Brasil. De fato, dificilmente professor (em geral um nativo) e alunos têm a mesma L1; no entanto, justamente porque nesse tipo de turma é comum que nem mesmo os alunos compartilhem a mesma L1, a possibilidade de haver momentos de tradução explicativa na definição lavaultiana é virtualmente nula, já que aí a L1 do professor é também a L2 estudada. Realmente, embora nesse tipo de sala os professores costumem mesmo usar apenas a L2 e cada aluno deva tentar acompanhar a aula como puder, não se pode falar nunca em uso da L1 em sala, como sugeriu Welker, e, da mesma forma, a definição de Lavault precisa ser corrigida. Afinal, mesmo em 
cursos de L2 de imersão, intensivos etc., é possível que os professores sintam eventualmente necessidade de tentar alcançar os alunos em uma língua que estes sabidamente entendam. Nesse caso, sim, a denominação tradução explicativa parece perfeitamente adequada, pois o docente precisará traduzir sua fala para uma terceira língua, diferente da sua L1 e da L2 em estudo.

Uma outra situação, um tanto mais incomum porém, na qual se veria o uso da tradução explicativa é possível. Imagine-se uma sala de LE em que professor e alunos não compartilhem nem a L1 nem o nível dos alunos na LE seja avançado. Nesse caso, para o professor se fazer entender, a tradução explicativa também teria de ocorrer numa terceira língua, isto é, nem na L1 dos envolvidos, nem na LE em estudo.

Assim, proponho essa nova diferenciação dos usos da tradução no ensino: (a) tradução pedagógica, isto é, exercícios de tradução; e (b) tradução explicativa, isto é, uso de uma língua diferente da L1 do professor e/ou dos alunos e da língua em estudo (LE ou L2) com fins explicativos. Além disso, há também (c) o uso da L1 em sala com fins explicativos, que alguns autores ainda consideram um tipo de tradução.

De qualquer maneira, conforme mencionado anteriormente, tanto o uso da tradução explicativa quanto o uso da L1 em sala não constituem um problema. Esses usos são antes um recurso - ou, por vezes, uma necessidade - por parte do professor ou dos alunos para ganhar tempo na comunicação ou para verificação da compreensão.

Já a tradução pedagógica, ou seja, os exercícios de tradução propriamente dita, para além de seu uso como recurso didático, pode ser considerada como um fim em si mesma, sendo valorizada como uma habilidade a mais para os aprendizes.

Como já comentado, o uso tradicional da tradução no MGT se dava pela memorização exaustiva de listas de palavras e de sentenças desconexas a serem traduzidas. Não é à toa então que, após sua queda, os novos defensores da tradução em aula tenham como bandeira que ela seja feita de forma contextualizada. No entanto, o que se percebe é que houve também, por parte de diversos teóricos, uma associação entre "contextualizada" e a utilização exclusiva de textos como material para tradução em sala de aula. Por exemplo, das seis propostas de exercícios de Atkinson (apud Romanelli, 2009, p. 217), cinco trabalham com textos escritos, sendo uma delas, inclusive, a tradução de um trecho de livro. A sexta proposta sugere que os alunos trabalhem como intérpretes, ou seja, mediando um diálogo entre falantes de línguas diferentes.

Welker (2003) faz notar em artigo dedicado ao tema, todavia, que mesmo a tradução de frases isoladas não é descabida, pois muitas frases podem ser traduzidas sem conhecimento de um contexto. Ou seja, desde que não se utilizem sentenças aparentemente sem nexo que deixem os alunos com uma frustrante impressão de jamais poderem ser utilizadas - vide a supracitada Socrates albus currit bene e outras tantas ainda mais estranhas encontradas nos manuais do MGT - também a tradução de 
pequenas frases pode ser útil. Para Welker (2003, p. 7), nos níveis iniciais, esse tipo de frase isolada tem o objetivo de conscientizar o aluno o mais cedo possível das peculiaridades da tradução, reservada para níveis mais avançados. Assim, tanto exercícios de tradução de frases isoladas e expressões simples de uso comum, como frases complexas que demonstrem pontos gramaticais estudados poderiam ter utilidade. Elisângela Liberatti (2012, p. 185), também em artigo, parece seguir essa linha de pensamento. Em seu texto, traz cinco sugestões de atividade, dentre as quais a primeira trata de "frases difíceis", a segunda de "expressões idiomáticas" e apenas uma trabalha com textos mais longos.

De fato, o uso exclusivo de textos nos exercícios de tradução parece querer restringir esse tipo de recurso didático a turmas de nível mais avançado ou, pelo menos, aos níveis iniciais e intermediários quando a L1 dos estudantes é próxima da LE, como é o caso de português e espanhol, por exemplo. Enquanto essas duas línguas têm grandes similaridades morfossintáticas e chegam a ter uma coincidência vocabular entre 85-89\% (dados retirados de Calvo Capilla; Ridd, 2009, p. 152), facilitando absurdamente o trabalho dos aprendizes inclusive ao fazer uma tradução, o mesmo não ocorre, naturalmente, com outras línguas - comparando com o português, especialmente as não latinas (e.g. alemão) e, mais especialmente ainda, as que não são do tronco indoeuropeu.

Deste último grupo, isto é, das línguas de troncos linguísticos diferentes do português, destaco situações de ensino-aprendizagem com as quais estou mais familiarizada e que envolvem, além do português, o japonês e o chinês.

\section{4) O ensino-aprendizagem de línguas distantes da L1}

Utilizando o Dicionário eletrônico Houaiss, o qual possui uma boa seção etimológica, tentei fazer uma pesquisa rápida por palavras portuguesas de origem chinesa. Embora a pesquisa não tenha sido completamente bem-sucedida e, portanto, não se possa apresentar uma lista exaustiva, apresento alguns resultados.

Percebi que muitas das palavras portuguesas de origem chinesa são derivadas de nomes próprios, por exemplo: "pequinês" < Pequim; "confucionismo" < Confúcio; "maoísmo" < Mao Tsé-Tung; "nanquim" < Nanquim.

Fora isso, surgiram ainda uns poucos outros vocábulos: "iuane" (moeda da China), "vampi" (um tipo de arbusto) e "ginseng" e "congo" (dois tipos de chá). E, aliás, a própria palavra "chá". Também há algumas palavras que não foram aportuguesadas, como "feng shui" e "kung fu".

No caso do japonês, devido à grande imigração japonesa para o Brasil ocorrida na primeira metade do séc. XX, a mesma pesquisa provavelmente teria um resultado mais profícuo, já que tudo indica que há mais palavras portuguesas de origem japonesa 
do que chinesa. Além da quantidade, não há tantas palavras derivadas de topônimos ou antropônimos, diferente do que ocorre no primeiro grupo. Alguns exemplos são "biombo", "judô", "bonsai", "zen” etc.

A falta de vocabulário em comum é apenas um exemplo do enorme abismo que separa essas três línguas, as quais pertencem a troncos linguísticos diferentes - o português faz parte do indo-europeu, o chinês do sino-tibetano, e o japonês é normalmente considerado uma língua isolada, embora, por vezes, seja associado às línguas altaicas. Em suma, o português soa tão alienígena para estudantes chineses e japoneses quanto o contrário.

Alia-se a isso o fato de que muito pouco se estudou sobre o ensinoaprendizagem quando as línguas envolvidas são muito distantes. Na verdade, é preciso lembrar que a maior parte dos estudos de ensino de línguas trata do ensino de inglês como L2/LE. Nesse tocante, relembro as palavras de Cook (2009, p. 113):

\begin{abstract}
Nos últimos anos, as ideias mais influentes sobre o ensino de línguas normalmente foram desenvolvidas com referências explícitas ao ensino de língua inglesa (ELI), acompanhadas por uma suposição tácita de que elas se aplicariam para o ensino de línguas em geral. Essa visão é reforçada pelo foco, advindo da linguística chomskiana, nos aspectos universais, em vez de em aspectos específicos, das línguas e da aquisição de língua. Argumentos relativos o uso pedagógico da tradução não são uma exceção a essas tendências gerais. A relevância das ideias de ELI para o ensino de outras línguas, contudo, não deve ser tomada como certa. O posicionamento pró ou contra a tradução pode variar de acordo com o relacionamento social e linguístico entre a $L 1$ e a L2 de um estudante. (grifos nossos) ${ }^{6}$
\end{abstract}

Isso não significa, obviamente, que nada possa ser aproveitado do que já foi estudado, mas, como Welker (2003, p. 1) também nota, é importante levar em conta o parentesco entre a língua materna e a língua estudada, especialmente pelo tipo de estrutura gramatical de ambas (e.g. flexional como o português, isolante como o chinês etc.).

Sob essa nova luz, volto então a pensar o uso ou não da tradução em sala de aula. Primeiramente, numa sala de LE distante da L1, acredito que o uso da L1 ou da tradução explicativa será ainda mais crucial do que no caso das línguas próximas. Se, como visto acima, o uso da L1/tradução explicativa é, hoje, visto como positivo - por ter um papel reafirmador dos conhecimentos dos alunos, por reduzir a ansiedade e por melhorar as relações afetivas em sala, por garantir um compartilhamento do poder dentro da sala, por ser uma ferramenta de elucidação, verificação e ganho de tempo dos professores -, enfim, se os teóricos concordam sobre os benefícios do uso da L1/tradução explicativa em sala, não será diferente no caso da sala com línguas distantes. 
Veja-se, por exemplo, o relato de Yoshifumi Saito em relação ao ensino de inglês no Japão (uma situação similar ao par português no Japão / japonês no Brasil):

considerando a vasta diferença linguística entre inglês e japonês em termos de grafologia, fonologia, fonética, vocabulário, sintaxe, semântica e estruturas discursivas, assim como o fato praticamente universal no ensino de línguas de que "os alunos sempre irão relacionar a nova língua à sua própria, mesmo que apenas em suas mentes" (Cook, 2010, p. 49), o fato é que quase sempre a tradução ou, pelo menos, a instrução em japonês facilita imensamente a compreensão que os alunos têm do inglês. (Saito, 2012 , p. 34, grifos nossos) $)^{7}$

De fato, principalmente nos níveis iniciais, requerer dos alunos a compreensão de uma língua completamente diferente da sua ou exigir dos docentes que se façam entender por mímica ou desenhos todo o tempo para evitar a tradução explicativa me parece comprometer por demais o andamento da aula. Além disso, como já foi enfatizado, acredito que aproveitar o conhecimento gramatical e cultural prévio dos alunos pode facilitar enormemente a compreensão da LE. Logo, quando o professor pode, através de explicações usando a L1 (ou uma terceira língua), fazer seus discípulos atentarem para alguma estrutura linguística ou fato cultural peculiar da LE, tanto mais proveitosa pode ser a aula.

Em minha experiência, tanto ensinando português como língua estrangeira, quanto ensinando japonês, percebo que o que mais motiva os alunos durante a aula são dúvidas a respeito da cultura brasileira ou japonesa - explicações que, dependendo do caso, seriam muito difíceis para eles se não fossem traduzidas ou feitas na L1.

Assim, por exemplo, nas aulas de japonês, muitas explicações giram em torno das formas de tratamento e de endereçamento. Há mais de um "eu" e, igualmente, mais de um "tu" e é preciso explicar aos alunos quando usar cada um deles, ou porque não devem usar alguns deles.

Da mesma forma, é preciso usar algum "sufixo de tratamento"8 junto ao nome das pessoas, o qual vai indicar seu grau de relacionamento e respeito em relação àquela pessoa (e.g. Fulano-san, Sicrano-sama, Beltrano-kun).

A gramática da língua japonesa também é profundamente diferente da portuguesa. A ordem das frases é SOV, o que por si só provoca grandes dificuldades para os alunos, mas, além disso, os verbos se flexionam em modo ${ }^{9}$, tempo e negação - e, no caso dessas duas últimas duas categorias, também alguns adjetivos fazem o mesmo. Então:

\begin{tabular}{|l|l|l|}
\hline & Presente/Futuro & Passado \\
\hline Afirmativa & $\begin{array}{r}\text { taberu (como, comes, come, } \\
\text { comemos, comem) }\end{array}$ & tabeta (comi, comeste...) \\
\cline { 2 - 3 } & oishii ([está] gostoso) & oishikatta ([estava] gostoso) \\
\hline
\end{tabular}




\begin{tabular}{|l|c|c|}
\hline Negativa & $\begin{array}{c}\text { tabenai (não como, não } \\
\text { comes...) }\end{array}$ & $\begin{array}{c}\text { tabenakatta } \text { (não comi, não } \\
\text { comeste...) }\end{array}$ \\
\cline { 2 - 3 } & $\begin{array}{c}\text { oishikunai ([não está] } \\
\text { gostoso) }\end{array}$ & $\begin{array}{c}\text { oishikunakatta } \text { ([não estava] } \\
\text { gostoso) }\end{array}$ \\
\hline
\end{tabular}

Exemplos de frases:

(a) Sushi tabeta? Oishikatta? = [Você] comeu sushi? [Estava] gostoso?

Note-se que diferentemente do que ocorre normalmente no português brasileiro, o sujeito da frase fica oculto. Naturalmente, por vezes, problemas de sentido vão acontecer:

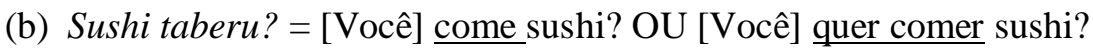

Nesse caso, o verbo no presente pode ser usado para se oferecer algo (sushi) ao interlocutor tanto quanto para perguntar se ele come ou não aquilo. O que quero demonstrar com esses exemplos é que o desafio cognitivo para os estudantes nesse caso abrange todos os graus da gramática (fonologia, morfologia e sintaxe), o léxico e ainda questões sócio-pragmáticas - o porquê da omissão do pronome (você/tu), quem é o interlocutor, quando é aceitável se referir a ele desta forma; e, em (b), como perceber qual dos sentidos foi falado.

No entanto, como se pode perceber pela simplicidade estrutural desses exemplos, logo se vê que costumam ser ensinados ainda nos níveis iniciais de estudo de japonês. Explicar esse tipo de detalhe em língua japonesa para um aluno brasileiro é, me parece, inviável. Saito (2012, p. 34-5) chega mesmo a dizer que, em níveis iniciais, mesmo a distinção entre uso da L1/tradução explicativa e tradução pedagógica faz pouco sentido:

\begin{abstract}
Alguns professores e pesquisadores fazem uma clara distinção entre instrução em L1 e tradução, aprovando a primeira e desaprovando a segunda, mas é extremamente difícil, embora possível teoricamente, evitar traduzir qualquer palavra, frase ou sentença no discurso alvo enquanto dando uma instrução em L1. A política que sugiro aqui é que tradução é apenas uma extensão da instrução elementar em L1, não uma habilidade especializada, como irei argumentar na próxima seção; ela deve funcionar como uma viga que o professor utiliza para sustentar a capacidade de seus alunos de usar inglês e que ele retira quando a estrutura sólida do prédio já está formada. (grifos nossos) ${ }^{10}$
\end{abstract}

Embora não chegue a concordar que esses dois tipos de tradução se confundam, é de se notar que, de fato, nos primeiros níveis, o professor de línguas distantes precisa virtualmente traduzir todas as palavras e frases para o aluno, antes que esse consiga começar a compreender a estrutura da LE.

Sendo assim, considero o uso da tradução explicativa essencial nesses casos. Quanto à tradução pedagógica, embora os livros didáticos de japonês e de português que conheço, em sua maioria, não costumem vir acompanhados de exercícios desse tipo, 
também a considero bastante proveitosa, especialmente em exercícios orais ou escritos de verificação da compreensão dos alunos sobre o que foi lido ou sobre algum novo ponto de gramática que foi estudado.

No tocante a este último uso, contudo, uma questão se impõe. Como se começou a discutir na seção anterior, atualmente o uso de exercícios de tradução tem sido aceito apenas quando ligado a textos, para se enfatizar a importância do contexto e evitar exercícios tradutórios de frases isoladas. Claro que não se pretende voltar a exercícios como os do MGT, porém costuma ser difícil, cansativo e frustrante para os alunos traduzir textos desde que se inicia o estudo de uma LE distante da sua L1.

$\mathrm{Na}$ minha experiência como professora de português para chineses, esse foi o caso: o livro que continha apenas textos fazia com que os alunos reclamassem profundamente. Por um lado, eles queriam a tradução completa do texto para sentirem que entenderam tudo, por outro era cansativo demais fazer isso sozinhos (e muitas vezes não tínhamos tempo suficiente para ler traduzindo em sala). O outro livro, que propunha exercícios de tradução de expressões ou frases isoladas, todas com as estruturas simples vistas ao longo da lição, dificilmente era alvo de grandes críticas e, melhor ainda, por vezes suscitava algumas discussões em sala porque uma frase poderia ser traduzida de diferentes maneiras - justamente pela falta de contexto. Por exemplo:

\begin{tabular}{|l|l|}
\hline \multirow{2}{*}{ Que dia é hoje? } & $\begin{array}{l}\text { Jintiān } x \bar{i} n g q \bar{j} \bar{l} ? \\
\text { (hoje é que dia da semana?) }\end{array}$ \\
\cline { 2 - 2 } & $\begin{array}{l}\text { Jintiān jĭháo? } \\
\text { (hoje é que dia do mês?) }\end{array}$ \\
\hline
\end{tabular}

\begin{tabular}{|l|l|}
\hline Meu professor & Wŏ de lăosh $\bar{\imath}$ \\
\cline { 1 - 2 } Minha professora & \\
\hline
\end{tabular}

Minha experiência lecionando para chineses, porém, rendeu mais questões. Até há pouco estive dando aulas de português na Universidade de Hebei, na China. Quando cheguei à China, eu não sabia dizer mais do que "obrigada" em mandarim. Meus alunos, por sua vez, não sabiam dizer sequer "obrigado" em português. Sendo assim, qualquer interação entre nós precisava ocorrer em uma outra língua, em geral o inglês. Normalmente as aulas de gramática dos níveis iniciais das línguas estrangeiras na Hebei são lecionadas por professores chineses, de modo que os professores nativos de uma LE só costumam ensinar para quem já sabe o básico. Até então, no entanto, a universidade ainda não tinha tido nenhum professor de língua portuguesa, cabendo a mim lecionar inclusive para alguns professores chineses. 
Numa situação assim, então, a tradução explicativa ocorria numa língua diferente da L1 da professora e da L1 dos alunos, e, obviamente, diferente da LE em estudo. Para piorar a situação, devido à distância entre a L1 dos alunos e a LE estudada face à relativa proximidade entre a LE e a língua de intercessão, isto é, português e inglês, percebi rapidamente que o inglês estava causando interferências no aprendizado deles, porque, por diversas vezes, os alunos misturavam as duas línguas ou até mesmo não conseguiam perceber diferença entre inglês e português. Assim, corriqueiramente confundiam palavras, como "chinês" e "chinese", "universidade" e "university" etc. fazendo frases mistas. Certa vez, uma aluna questionou a frase "Eu tenho xx anos", indagando porque deveria usar o verbo "ter" se em inglês o verbo correto era "to be"...

Não é à toa então que a maioria dos teóricos costume condenar a tradução em sala quando não há apenas uma L1:

As escolas de línguas em países anglófonos atendem a turmas de visitantes e migrantes de background linguístico misto, tornando a tradução impossível. (Cook, 2009, p. 114, grifos nossos) $)^{11}$

Não estou me negando a conduzir atividades sem tradução na sala de aula, nem acho que seria sábio ou, até mesmo, possível trazer a tradução para turmas de línguas mistas, onde estudantes falam línguas diferentes. (Saito, 2012, p. 28, grifos nossos) ${ }^{12}$

Neste ponto de minha pesquisa, não tenho argumentos suficientes para confrontar tais afirmações, mas, dada minha experiência de um ano na China, tenho como hipótese que talvez seja possível o uso da tradução pedagógica quando o professor não compartilha da L1 de seus alunos - embora em meu caso não se tratasse de uma classe mista, mas apenas um caso em que o professor não dominava a L1 dos alunos.

Realmente, quando a L1 dos alunos é estranha ao professor, posicionar-se contra a tradução parece fazer sentido, especialmente quando se trata da tradução de textos complexos. No entanto, talvez o uso de frases isoladas ou mesmo de textos curtos ainda seja uma boa opção. Além disso, existem diversos tipos de exercícios e recursos diferentes que o professor pode utilizar - inclusive exercícios de tradução reversa - que possivelmente poderiam contornar a situação.

Meus próximos passos caminham nessa direção, tentando encontrar novas fontes de reflexão sobre o ensino-aprendizagem de línguas distantes e procurando experiências e propostas de exercícios que possam contemplar esse tipo de sala de aula.

\section{5) À guisa de conclusão}

Este artigo pretendeu apresentar a proposta de minha pesquisa de doutorado sobre o uso da tradução no ensino de línguas não maternas. 
Além de olhar brevemente para a longa tradição de exercícios de tradução no ensino de LEs e de L2, procurei demonstrar por que, a despeito das críticas feitas a esta tradição ao longo do séc. XX, a tradução continua e deve continuar a ser utilizada nas salas de aula.

Ademais, tratei de uma questão mais específica, isto é, situações relacionadas ao uso da tradução quando a LE em estudo é uma língua distante da L1 dos alunos e, ainda mais especificamente, no caso de haver também uma barreira igual entre alunos e professor. Enfim, me pergunto: a tradução pedagógica é possível se o professor não é proficiente na L1 de seus alunos? Mesmo se forem turmas de níveis iniciais? E se forem turmas com LMs mistas?

No estágio atual de minha pesquisa, não sou capaz de responder satisfatoriamente a essas perguntas. A partir de agora, espero continuar pesquisando, recolhendo dados e refletindo sobre experiências de professores, no sentido de tentar obter respostas e de analisar as diversas sugestões de exercícios de tradução encontradas na literatura.

\footnotetext{
${ }^{1}$ Com "tradução interlingual" me refiro ao conhecido conceito de Roman Jakobson (1973), que dividiu a tradução em três tipos: intralingual (dentro de uma mesma língua), interlingual ou propriamente dita (de uma língua para outra) e intersemiótica (de um meio para outro, e.g. um texto para uma peça de teatro).

${ }^{2}$ Todas as citações têm neste artigo foram traduzidas por mim, exceto quando indicado em contrário. Eis o texto original: "pedagogically, it [imitatio] was used for revision exercises, in which students were taught to write or orate by rewriting or respeaking classic texts - changing them in some significant way, choosing new words for saying the same thing".

${ }^{3}$ Grammar-translation requires learners to focus on individual grammar points, which are taught deductively. Example sentences are then translated both from and to the L2 [...] Grammar-translation thus focuses on accuracy and written rather than spoken language, with language being broken down and analysed at the level of words, phrases and individual sentences in the first instance

${ }^{4}$ Every thought of promoting practical skills that might be of immediate use in everyday life had to be discarded. The sole aim of language teaching was to be the improvement of the mind.

${ }^{5}$ In each lesson first a detailed set of rules on a particular grammar item (e.g., the pronouns) followed by portions of sentences to be translated into the target language and by a list of word-equations. Apart from some short anecdotes and poems in the appendix to the book, the learners never read a single sentence in the foreign language; they had to make up the target language synthetically from the rules and word-lists of the book. In that way, the pupils exercised their memories, learnt to make grammatical distinctions in accordance with Latin grammar, and to handle the various elements of language in the translation tasks.

${ }^{6}$ In recent years, the most influential ideas about language teaching have often been developed with explicit reference to English Language Teaching (ELT), accompanied by an implicit assumption that they apply to foreign language teaching in general. This view is strengthened by the focus of attention, deriving from Chomskyan linguistics, on universal rather than language-specific aspects of language and language acquisition. Arguments concerning the pedagogic use of translation are no exception to the influence of these general trends. The relevance of ideas from ELT to the teaching of other languages, however, should not be taken for granted. The case for and against translation may vary with the social and linguistic relationship between a student's $L 1$ and $L 2$.
} 
${ }^{7}$ considering the wide linguistic difference between English and Japanese in terms of graphology, phonology, phonetics, vocabulary, syntax, semantics, and discoursal structures as well as the almost universal fact of language learning that '[1]earners will always relate the new language to their own, even if only in their own minds' (Cook, 2010: 49), it is quite often the case that translation or at least instruction in Japanese greatly facilitates their understanding of English.

${ }^{8}$ Sem querer me ater à terminologia da descrição gramatical do japonês, tento traçar apenas um paralelo com a gramática do português a título de facilitar a compreensão do leitor que não esteja familiarizado com aquela língua.

${ }^{9}$ Conferir a nota anterior. Por "modo" tento exemplificar a diferença, por exemplo, entre "taberu" e "taberareru", em que o morfema -rare é inserido para indicar "possibilidade ou capacidade".

${ }^{10}$ Some teachers and researchers make a clear distinction between instruction in L1 and translation, approving of the former and disapproving of the latter, but it is extremely difficult, though possible in theory, to avoid translating any word, phrase or sentence in the target discourse while giving instruction in L1. The policy I would suggest here is that translation is just an extension of elementary L1 instruction, not a specialized skill, as I will argue in the next section; it should function as a scaffolding that the teacher puts up to build up his/her students' ability to use English and takes down when the solid framework of the building has been set up.

${ }^{11}$ Language schools in English speaking countries cater for classes of visitors and immigrants from mixed linguistic background, making translation impossible

${ }^{12} \mathrm{I}$ am not objecting to conducting classroom activities translation-free, nor is it wise or even realistic to bring it into mixed language classes where students speak different languages.

\section{Referências}

CALVO CAPILLA, María; RIDD, Mark. A tradução como atividade contrastiva e de conscientização na aprendizagem de línguas próximas. Horizontes de Linguística Aplicada, Brasília - DF, v. 8, n. 2, p. 150-169, 2009. Disponível em: <http://seer.bce.unb.br/index.php/horizontesla/article/view/2939>. Acesso em: 18 nov. 13.

CÍCERO, Marco Túlio; VIEIRA, Brunno Vinicius Gonçalves; ZOPPI, Pedro Colombaroli. De optimo genere oratorum. Scientia Traductionis, Florianópolis, n.10, 2011. Disponível em: <https://periodicos.ufsc.br/index.php/scientia/article/view/19804237.2011n10p4>. Acesso em: 18 nov. 13.

COOK, Guy. Language teaching. In: BAKER, Mona (org.). Routledge encyclopedia of translation studies. 2. Ed. Londres; Nova Iorque: Routledge, 2009. p.112-3.

Dicionário eletrônico Houaiss da língua portuguesa. Rio de Janeiro: Objetiva, 2009. Versão 3.0

HALL, Graham. Exploring English language teaching: language in action. Londres; Nova Iorque: Routledge, 2011.

JAKOBSON, Roman. Dois aspectos da linguagem e dois tipos de afasia. In: Linguística e comunicação. São Paulo: Cultrix, 1973. p. 34 -62. 
LIBERATTI, Elisângela. A tradução na sala de aula de LE: (des)construindo conceitos. Entrepalavras, Fortaleza, ano 2, v. 2, n. 1, p. 175-187, jan.-jul. 2012. Disponível em: $<$ http://www.entrepalavras.ufc.br/revista/index.php/Revista/article/view/50/0>. Acesso em: 18 nov. 13.

MACHT, Konrad. Practical skills or mental training? The historical dilemma of foreign language methodology in nineteenth and twentieth century Germany. Paradigm, Augsburg, n. 14, $\quad$ sep. 1994. Disponível em: <http://faculty.education.illinois.edu/westbury/paradigm/macht.html>. Acesso em: 18 nov. 13.

ROBINSON, Douglas. Imitation. In: BAKER, Mona (org.). Routledge encyclopedia of translation studies. Londres; Nova Iorque: Routledge, 2001. p. 111-2.

ROMANELLI, Sergio. O uso da tradução no ensino-aprendizagem das línguas estrangeiras. Horizontes de Linguística Aplicada, Brasília - DF, v. 8, n. 2, p. 200-219, 2009. Disponível em: <http://seer.bce.unb.br/index.php/horizontesla/article/view/2942>. Acesso em: 18 nov. 13.

SAITO, Yoshifumi. Translation in English language teaching in Japan. KJEE, Tóquio, v. 3, 2012. Disponível em: 〈http://park.itc.u-tokyo.ac.jp/eigo/KJEE/003/027-036.pdf>. Acesso em: 18 nov. 13.

SCATOLIN, Adriano. A invenção no "Do orador" de Cícero: um estudo à luz de "Ad familiares I, 9, 23”. 2009. 308 f. Tese (Doutorado em Letras Clássicas) - USP, São Paulo, 2009. Disponível em: <http://www.teses.usp.br/teses/disponiveis/8/8143/tde19022010-165443/en.php>. Acesso em: 18 nov. 13.

SOUZA CORRÊA, Elisa F. Socrates currit bene: um breve passeio pela história da gramática. Soletras, São Gonçalo, ano 10, n. 19, jan.-jun. 2010. Disponível em: <http://www.filologia.org.br/soletras/19/indice.htm>. Acesso em: 18 nov. 13.

WEEDWOOD, Barbara. História concisa da linguística. São Paulo: Parábola, 2008.

WELKER, Herbert A. Traduzir frases isoladas na aula de língua estrangeira: por que não? Horizontes de Lingüística Aplicada, Brasília - DF, vol. 2, n. 2, p. 149-162, 2003. Disponível em: <http://www.pgla.unb.br/hawelker/images/stories/professores/documentos/tradfras.pdf $>$. Acesso em: 18 nov. 13. 